\title{
SIGNOS QUÍMICOS: UM OBJETO DE APRENDIZAGEM PARA APROPRIAÇÃO DAS REPRESENTAÇÕES NO ENSINO DE QUÍMICA
}

\author{
Thais Adrianne Silva Reinaldo \\ Ana Maria de Andrade Caldeira
}

\section{Introdução}

As Ciências da Natureza possuem uma linguagem específica, a linguagem científica, com uma forma característica de representar e dar significado, e, portanto, a apropriação da linguagem científica deve ser objetivo do ensino dessas Ciências, pois como afirmam Machado e Mortimer (2012), "a aprendizagem da Ciência é inseparável da aprendizagem de sua linguagem”.

O ensino das Ciências da Natureza deve propiciar a Alfabetização Científica, que segundo Chassot (2003) é o processo pelo qual um indivíduo adquire conhecimentos científicos fundamentais para a compreensão destes conceitos em situações cotidianas, de forma crítica e reflexiva, e envolve o desenvolvimento de habilidades para compreensão básica de termos e representações científicas. 
No ensino de Química a necessidade de compreensão e apropriação da linguagem é muito evidente, pois além da compreensão da linguagem comum e das especificidades da linguagem científica, existe a necessidade de interpretação da linguagem química, com seus símbolos, fórmulas, equações e termos para explicar modelos abstratos.

Todavia, um dos entraves mais frequentes no processo de ensino e aprendizagem da Química é a dificuldade dos estudantes em compreender e interpretar a linguagem científica e, mais especificamente, a linguagem representacional química. Aliado a isto, existe uma escassez de materiais didáticos elaborados para auxiliar a lidar com este entrave. Diante disso, o professor por vezes acaba não sabendo como proceder, tornando-se um obstáculo para aprendizagem.

Em vista disso, foi elaborado o produto educacional apresentado neste trabalho, com o objetivo de propiciar uma alternativa didática para apropriação das representações químicas na Educação Básica.

Trata-se de um recurso didático do tipo Objeto de Aprendizagem (OA), que corresponde a qualquer recurso digital com finalidade pedagógica. De acordo com a síntese de Sabbatini (2012), os objetos de aprendizagem podem ser desenvolvidos em qualquer formato ou mídia, porém se distinguem de outros recursos didáticos por 
aspectos como a possibilidade de uso em diferentes contextos educativos (reutilização), a possibilidade de utilização em diferentes plataformas técnicas (portabilidade), conter ou estar contido em outros objetos (modularidade) e ter sentido de forma independente a outros objetos (autossuficiência).

Este Objeto de Aprendizagem é constituído por módulos, como a definição de OA explicita, referentes a jogos digitais educacionais, que possuem sentido próprio, mas podem ser explorados concomitantemente, dependendo do objetivo educacional proposto para esta utilização na ação didática.

Segundo Savi e Ulbricht (2008, p. 10), “jogos educacionais bem projetados podem ser criados e utilizados para unir práticas educativas com recursos multimídia em ambientes lúdicos a fim de estimular e enriquecer as atividades de ensino e aprendizagem", sendo esta a finalidade deste OA.

Entre os benefícios que os jogos digitais educacionais podem proporcionar aos processos de ensino e aprendizagem, ainda conforme Savi e Ulbricht (2008), pode-se citar: motivação; facilitação da aprendizagem; aprendizado por descoberta; experiência de novas identidades; socialização; e, desenvolvimento de habilidades cognitivas, da coordenação motora e/ou comportamento expert. 
Neste sentido, foi desenvolvido este recurso educacional cuja pesquisa e referenciais teóricos de fundamentação são descritos na sequência.

\section{Embasamento teórico e investigativo}

Aprender Química deve possibilitar ao indivíduo entender a constituição, as propriedades e as transformações da matéria em diferentes aspectos, ou seja, deve propiciar a percepção dos fenômenos aliada à compreensão das teorias e modelos explicativos, utilizando a linguagem química.

Portanto, a aprendizagem de conceitos químicos envolve a observação de fenômenos em nível macroscópico, a compreensão destes em nível microscópico bem como a expressão de tais interpretações por meio de representações, nível simbólico.

Os níveis macroscópico, submicroscópico e simbólico correspondem aos três níveis de representação e pensamento dos conhecimentos químicos propostos por Johnstone (1982) e reelaborados em Johnstone (1993). No Brasil, estes níveis foram redefinidos por Mortimer, Machado e Romanelli (2000) como os aspectos dos conhecimentos químicos e denominados como fenomenológico, teórico e representacional, respectivamente. 
O nível macroscópico se refere tanto aos fenômenos concretos e perceptíveis, naturais ou reproduzidos por experimentos, quanto aos fenômenos materializados em situações reais e cotidianas. Já o nível submicroscópico se refere as explicações teóricas e modelos para interpretação molecular dos fenômenos químicos. E o nível simbólico se refere as representações simbólicas químicas que possibilita a relação entre os outros dois níveis.

Sendo assim, aprender Química requer a articulação entre os três níveis de representação e pensamento dos conhecimentos químicos, tornando-se necessário certo entendimento dos processos de significação envolvidos para tanto, conforme salientam Gois e Giordan (2007, p.36):

[...] o conhecimento químico dispõe de formas gráficas e fonéticas peculiares que são usadas quando lidamos com a interpretação de fenômenos da transformação dos materiais. O modo como essas representações promovem seus significados e a compreensão das ações que tem lugar durante o desenvolvimento das atividades de ensino são questões importantes no ensino da Química, em especial quando a natureza dessas representações é circunscrita às suas funções de mediação e de constituição do conhecimento. 
Neste sentido, a teoria Semiótica de Peirce (1995) pode servir de fundamentação para o estudo das representações e processos de significação envolvidos. Criada por Charles Sanders Peirce (1839-1914), a Semiótica é a ciência geral de toda e qualquer linguagem.

Mais especificamente, "a semiótica é a ciência dos signos e dos processos cognitivos (semiose) na natureza e na cultura", como defini Noth (1995, p. 17), e "tem por função classificar e descrever todos os tipos de signos logicamente possíveis", como explica Santaella (2007, p. 29). Já signo, por sua vez, "é qualquer coisa que se produz na consciência”, conforme Santaella (2007, p.53).

Como explicita Santaella (2007), esta teoria considera que toda e qualquer experiência reconhecida pelo sujeito, isto é, tudo aquilo que de algum modo e sentido esteja presente à mente, aparece à consciência em uma progressão de três elementos formais que correspondem às três categorias universais do pensamento, a saber: primeiridade, secundidade e terceiridade. A primeiridade corresponde a apreensão das coisas, consciência imediata advinda do ser e sentir. A secundidade corresponde a reação à sensação transmitida ao indivíduo pelo objeto. Já a terceiridade corresponde a concatenação das categorias anteriores por meio da abstração.

Assim, do mesmo modo como a aprendizagem de linguagens passa por esta relação triádica das categorias 
de pensamento, a apropriação da linguagem química também deve passar por tais categorias para, então, propiciar uma correta associação dos signos químicos com os conhecimentos químicos em seus diferentes níveis de representação.

Isto posto, o recurso educacional apresentado neste trabalho é produto resultante de uma pesquisa com tal fundamentação teórica, descrita em Reinaldo (2019a), que objetivou de modo geral propor, aplicar e avaliar um método de ensino, fundamentado na Semiótica de Peirce (1995), para facilitar a apropriação da linguagem química na Educação Básica, considerando os níveis de representação e pensamento de Johnstone (1993). De forma específica, esta investigação buscou estruturar e aplicar atividades didáticas, empregando-se abordagens diversificadas, recursos selecionados e materiais produzidos, visando propiciar a compreensão dos níveis e representações de conhecimentos químicos.

Os resultados obtidos demonstraram desenvolvimento das habilidades cognitivas definidas e apropriação dos conceitos científicos ensinados por todos os sujeitos. A pesquisa comprovou a relevância das representações e das interpretações conferidas a estas para a aprendizagem em Química e igualmente a importância da abordagem dos três níveis dos conhecimentos químicos e suas respectivas formas de representação para a significação da linguagem química, ressaltando-se, assim, a im- 
portância de se considerar os processos de significação realizados pelos estudantes e a pertinência da metodologia com fundamentação Semiótica.

As demandas e resultados satisfatórios das atividades didáticas aplicadas culminaram na idealização e desenvolvimento deste objeto educacional, como um material de aprendizagem alternativo para apropriação das representações em Química. O contexto de idealização e produção deste recurso educacional é descrito na sequência.

\section{Contexto de produção}

O produto educacional aqui apresentado foi elaborado a partir de uma pesquisa em nível de Mestrado visto que, por seu caráter Profissional, além da dissertação, é uma das exigências do Programa de Pós-Graduação em Docência para a Educação Básica, oferecido pela Faculdade de Ciências, da Universidade Estadual Paulista "Júlio de Mesquita Filho".

Para auxiliar a pesquisa e elaboração destes produtos por seus mestrandos, este programa criou o Laboratório de Desenvolvimento de Pesquisas e Produtos Educacionais (LADEPPE). Na época de desenvolvimento deste produto, era coordenado pelas professoras Ana Maria de Andrade Caldeira e Thaís Cristina Rodrigues Teza- 
ni, com associação de graduandos dos cursos de Design, Ciência da Computação e outros correlatos.

O LADEPPE é responsável por pesquisar as possibilidades, os processos e as tecnologias educacionais para a Transposição Didática bem como desenvolver Mídias Didáticas. Os produtos desenvolvidos ficam disponibilizados no Repositório eduCAPES, o portal de objetos educacionais abertos para uso de estudantes e professores desenvolvido pela Coordenação de Aperfeiçoamento de Pessoal de Nível Superior (CAPES), fundação do Ministério da Educação (BRASIL, 2020).

As características e funcionalidades deste produto educacional, fruto de uma pesquisa, são descritas a seguir.

\section{Objeto de aprendizagem "Signos Químicos"}

O produto educacional, resultante da pesquisa explicitada anteriormente, é um recurso audiovisual do tipo jogo digital. Trata-se de um Objeto de Aprendizagem e tem como público-alvo estudantes e professores cursando os anos finais do Ensino Fundamental ou o Ensino Médio.

Optou-se por este produto pela possibilidade de sua utilização como um recurso didático alternativo e facilitador para o ensino da linguagem representacional 
química, cuja abordagem deve ocorrer a partir dos anos finais do Ensino Fundamental, de acordo com a Base Nacional Comum Curricular (BRASIL, 2018).

Este Objeto de Aprendizagem visa propiciar a significação de diferentes tipos de representações, dentre estas as relacionadas aos níveis dos conhecimentos químicos e por esta razão foi intitulado Signos Químicos.

Como se propõe um OA, este produto educacional pode ser utilizado em diferentes contextos educativos, assim como em momentos pedagógicos diversificados na ação didática, sendo, portanto, uma ferramenta didática para diferentes finalidades, tais como: o levantamento de concepções prévias, a introdução e sensibilização à temática, desenvolvimento de conteúdos, ou a avaliação da aprendizagem.

Além disto, é um recurso de fácil acesso, por ser de domínio público e disponibilizado no Portal eduCAPES (REINALDO, 2019b), bem como de fácil utilização, por ser digital e funcionar sem a necessidade de conexão à internet ou a qualquer rede de computadores (off-line), assim, não necessita de muitos preparativos prévios e recursos para sua execução.

Por ser aplicável a diferentes momentos pedagógicos, a exploração e aproveitamento do OA pode ocorrer de forma demonstrativa pelo professor para ilustração da 
temática abordada, com o uso apenas de um computador e um projetor, caso não haja recursos informáticos para exploração pelos estudantes ou for a preferência do docente.

De modo geral, Signos Químicos disponibiliza ao professor ferramentas visuais para abordagem de conceitos relacionados a constituição da matéria, de maneira a propiciar motivação e reflexão dos estudantes.

Ressalta-se que este OA é fruto das demandas decorrentes bem como dos resultados satisfatórios de atividades didáticas desenvolvidas e analisadas na pesquisa já explicitada (REINALDO, 2019a), e, portanto, fundamentado no referencial teórico da mesma. Para tanto, este objeto é composto por três jogos, Isto é..., Níveis e zoOM, que visam desenvolver as habilidades cognitivas apresentadas no Quadro 1.

Quadro 1: Habilidades cognitivas propiciadas pelo produto técnico "Signos Químicos"

\begin{tabular}{|c|c|c|c|}
\cline { 2 - 4 } \multicolumn{1}{c|}{} & Observar & Relacionar & Conhecer \\
\hline $\begin{array}{c}\text { Jogo 1 } \\
\text { "Isto é } \\
\text {..." }\end{array}$ & $\begin{array}{c}\text { Identificar ima- } \\
\text { gens como repre- } \\
\text { sentações. }\end{array}$ & $\begin{array}{c}\text { Diferenciar os } \\
\text { conceitos repre- }\end{array}$ & $\begin{array}{c}\text { Classificar ima- } \\
\text { gens em represen- } \\
\text { sação, modelo e e modelo e } \\
\text { símbolo }\end{array}$ \\
\hline
\end{tabular}




\begin{tabular}{|c|c|c|c|}
\hline $\begin{array}{c}\text { Jogo } 2 \\
\text { "Níveis" }\end{array}$ & $\begin{array}{l}\text { Reconhecer a } \\
\text { existência de dife- } \\
\text { rentes representa- } \\
\text { ções dos materiais } \\
\text { e seus constituin- } \\
\text { tes. }\end{array}$ & $\begin{array}{l}\text { Relacionar os } \\
\text { níveis macroscópi- } \\
\text { co (observável), } \\
\text { submicroscópico } \\
\text { (modelos) e repre- } \\
\text { sentacional (sim- } \\
\text { bólico) da matéria. }\end{array}$ & $\begin{array}{l}\text { Compreender a } \\
\text { matéria e seus } \\
\text { constituintes em } \\
\text { seus diferentes } \\
\text { níveis (macroscó- } \\
\text { pico, submicros- } \\
\text { cópico e represen- } \\
\text { tacional). }\end{array}$ \\
\hline $\begin{array}{c}\text { Jogo } 3 \\
\text { "zoOM" }\end{array}$ & $\begin{array}{c}\text { Reconhecer a } \\
\text { existência de di- } \\
\text { mensões entre os } \\
\text { seres e seus consti- } \\
\text { tuintes. }\end{array}$ & $\begin{array}{c}\text { Relacionar as } \\
\text { dimensões dos } \\
\text { seres e seus consti- } \\
\text { tuintes com escalas } \\
\text { de medidas }\end{array}$ & $\begin{array}{c}\text { Classificar em } \\
\text { ordem de grandeza } \\
\text { as representações } \\
\text { de seres e seus } \\
\text { constituintes. }\end{array}$ \\
\hline
\end{tabular}

Fonte: Autoras

Conforme descrito no Quadro 1, cada jogo pode propiciar o desenvolvimento de três habilidades cognitivas, dependendo do nível de abstração. Tal divisão foi fundamentada na Semiótica de Peirce (1995), referencial teórico do estudo, e estabelecida para contemplar os três níveis do processo de aprendizagem Observar, Relacionar e Conhecer que se correlacionam com as categorias universais do pensamento propostas por Peirce (1995), e correspondem às categorias primeiridade, secundidade e terceiridade, respectivamente.

Assim sendo, os jogos propostos neste OA buscaram a sensibilização à temática e/ou a mobilização dos conceitos já ensinados por meio de um recurso digital interativo, que podem ser explorados separadamente ou combinados. 
A tela inicial do OA Signos Químicos, demostrada na Figura 1, apresenta ao jogador o nome deste produto educacional, o tradicional botão para sair $(X)$ e um menu com quatro opções para seleção por meio de botões.

Figura 1: Tela inicial do OA

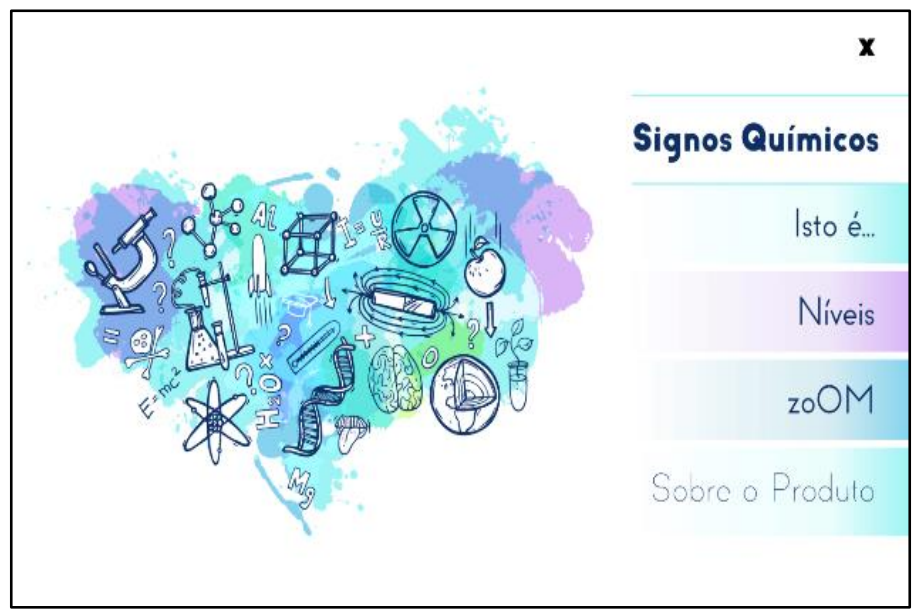

Fonte: Autoras

Três destas opções correspondem aos nomes dos três jogos: Isto é..., Níveis e zoOM. Já a quarta opção, Sobre o Produto, apresenta os responsáveis pela elaboração e desenvolvimento do OA, ao ser selecionada, conforme Figura 2. 
Figura 2: Tela da opção Sobre o Produto

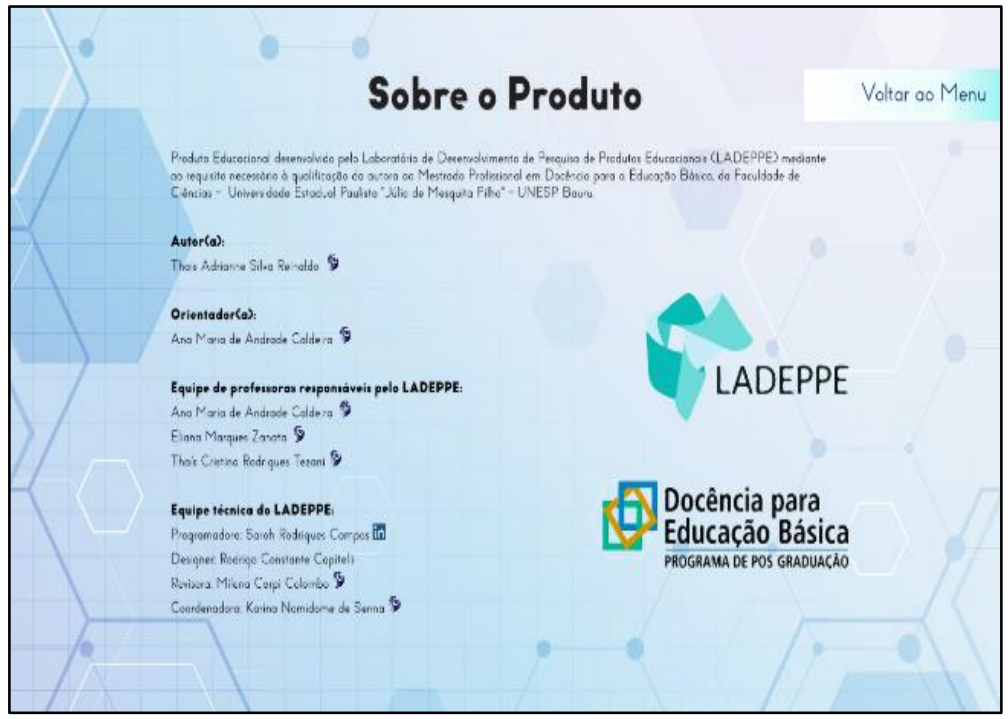

Fonte: Autoras

O objetivo, conteúdo e ações de cada jogo, correspondentes as outras três opções da tela inicial, são detalhados na sequência.

\section{Jogo "Isto é..."}

O primeiro jogo, Isto é..., aborda os conceitos representação, modelo e símbolo. Este jogo foi elaborado devido a uma necessidade teórica comprovada pelos dados obtidos no desenvolvimento da pesquisa supracitada e visa propiciar o reconhecimento, compreensão e diferenciação destes conceitos. A adequada compreensão 
destes conceitos pelo estudante é fundamental para que este reconheça e entenda a dimensão constitutiva dos modelos e símbolos químicos, evitando assim entraves na interpretação da linguagem química bem como na abstração de metáforas, analogias e modelos visuais muito utilizados no ensino de Química.

Ao selecionar a primeira opção, correspondente ao jogo Isto é..., surge uma outra tela, apresentada na Figura 3(a), informando ao jogador sobre o nível inicial do jogo (Nível Fácil), o tempo que este terá para jogar (30 segundos), o botão para iniciar o jogo (Começar) e o botão para retornar ao menu inicial (Voltar ao Menu).

Figura 3: Tela iniciais de cada nível do jogo 1 "Isto é...” do OA

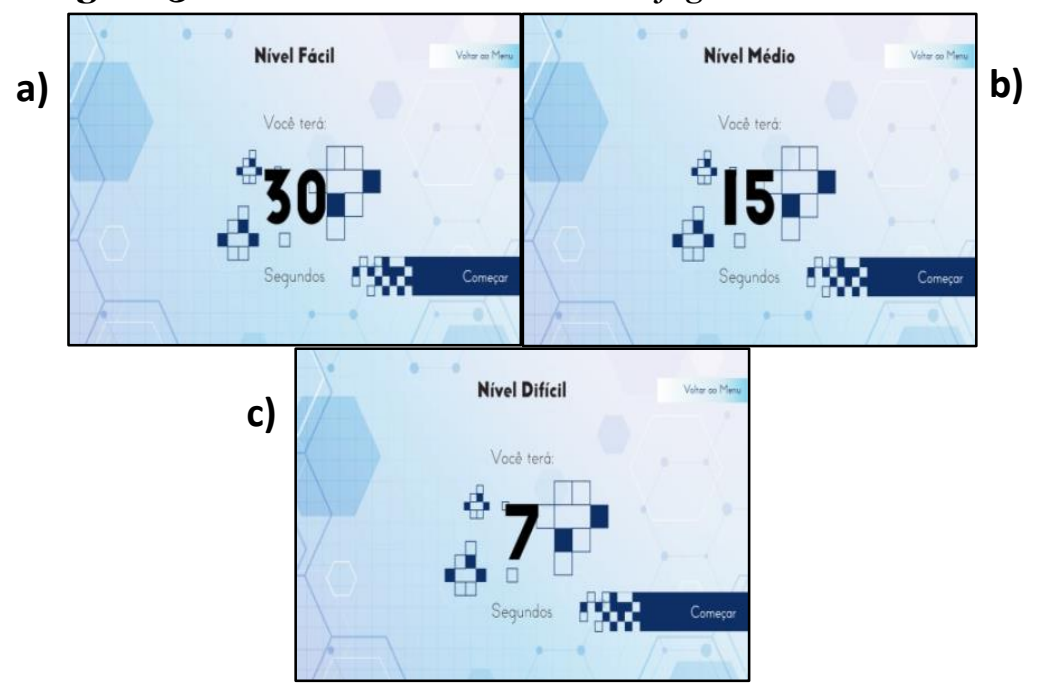

Fonte: Autoras 
Selecionando a opção Começar, é apresentada uma tela contendo o título do jogo 1, uma imagem a ser classificada, quatro opções de resposta na forma de botões e um temporizador, além do botão para retornar ao menu inicial, como demonstra a Figura 4.

Figura 4: Exemplo de tela de uma rodada do jogo 1

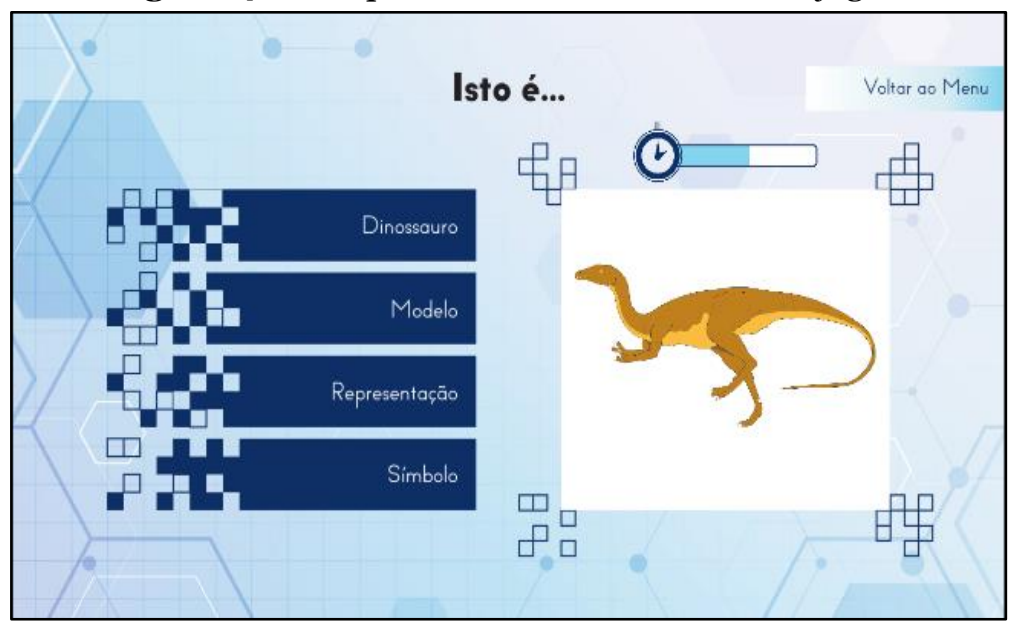

Fonte: Autoras

Esta tela corresponde a primeira de três etapas, denominadas rodadas, deste nível do jogo. Em cada rodada o jogador tem o tempo determinado para interpretar uma imagem e completar o enunciado, que é o próprio título do jogo, selecionando uma das quatro opções apresentadas. Dentre estas opções, três são constantes, representação, modelo e símbolo, visto que se referem aos conceitos explorados neste jogo. 
A imagem apresentada em cada rodada pode ser de um objeto do cotidiano ou ser vivo (representação); a representação de uma ideia, tais como animais extintos e pré-históricos, personagens mitológicos e lendários (modelo); ou a representação de uma imagem dotada de significado para uma certa comunidade, como placas de trânsito, trecho de uma partitura e palavras (símbolo).

Assim que uma opção de resposta é selecionada surge uma tela de correção, como as apresentadas na Figura 5, indicando se a resposta dada estava correta ou qual deveria ser a resposta correta.

Figura 5: Telas de correção às respostas dadas nas rodadas do jogo 1

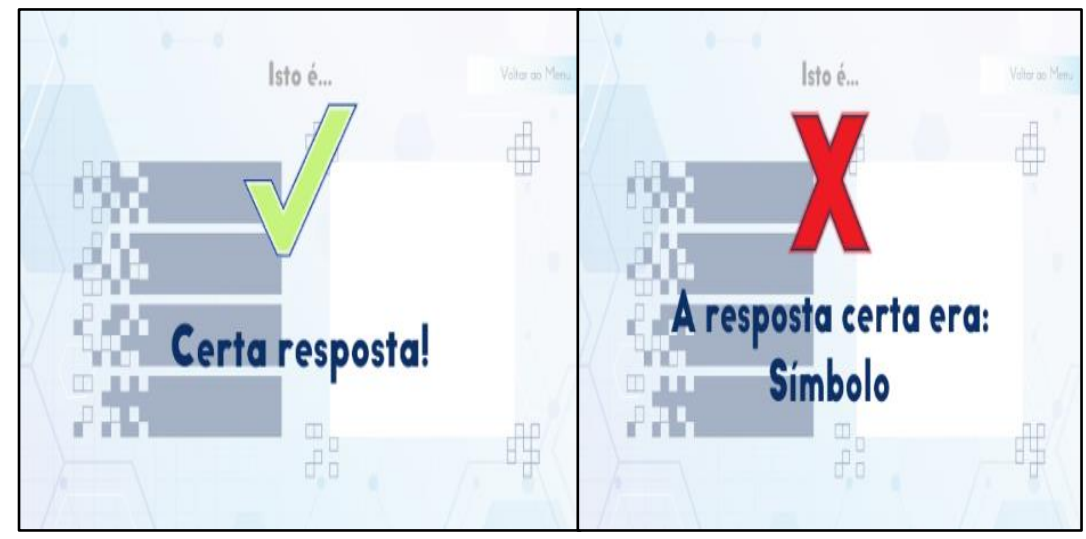

Fonte: Autoras 
Caso o jogador não selecione uma resposta no tempo estabelecido aparece uma tela indicando o término do tempo na rodada, conforme Figura 6.

Figura 6: Tela indicando o término do tempo de resposta em uma rodada do jogo 1

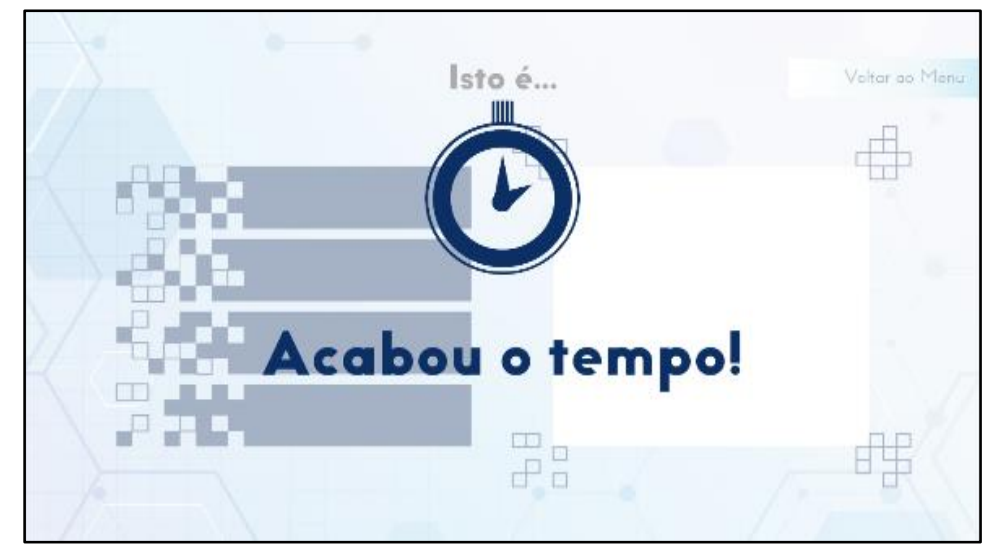

Fonte: Autoras

Após a correção da resposta escolhida ou indicação do término do tempo da rodada, automaticamente surge outra tela, semelhante à Figura 5, com uma nova imagem a ser classificada, num total de três rodadas no Nível Fácil.

A cada rodada são somados os pontos relativos ao tempo restante após a seleção da resposta, ou seja, os pontos de cada rodada equivalem ao tempo restante até o momento da escolha do jogador. Caso o jogador não 
escolha uma opção dentro do prazo estabelecido não obterá pontos.

Findando as três rodadas deste nível, surge automaticamente uma tela indicando o próximo nível, Nível Médio, apresentada na Figura 3(b). Neste segundo nível o tempo de resposta é de até 15 segundos e são apresentadas quatro imagens para classificação, ou seja, é composto de quatro rodadas.

Concluídas as rodadas deste nível, surge automaticamente a tela indicando o terceiro e último nível deste jogo, Nível Difícil, apresenta na Figura 3(c), contendo o tempo de resposta em cada rodada, equivalente a $7 \mathrm{se}-$ gundos. Este nível é composto por sete rodadas.

Assim sendo, este jogo é composto de três níveis de dificuldade que diferem em relação ao tempo para escolha da resposta e a quantidade de imagens a serem classificadas.

A pontuação é a somatória dos segundos restantes em cada rodada, apresentada ao ser finalizada a última rodada do terceiro nível, em uma tela como a demonstrada na Figura 7 com a indicação do fim do jogo, os pontos atingidos e as opções Voltar ao Menu, que retorna à tela inicial do OA (Figura 1), ou Jogar Novamente, que retorna à tela inicial do jogo 1, já apresentada na Figura 3(a). 
Figura 7: Tela final do jogo 1

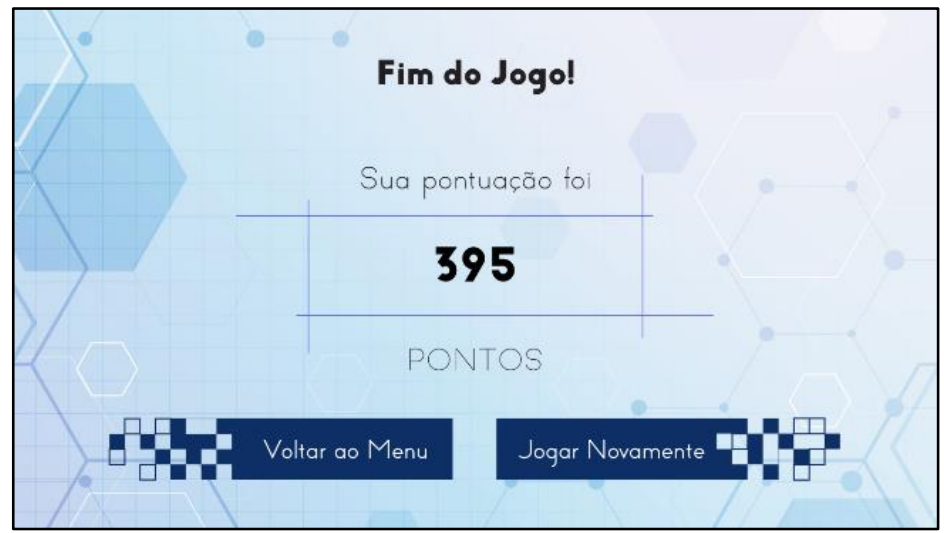

Fonte: Autoras

\section{Jogo "Níveis"}

Este segundo jogo trata-se da virtualização de um dos materiais de aprendizagem elaborados para as atividades didáticas desenvolvidas na pesquisa, utilizado em sala de aula e com bons resultados, tanto para levantamento de concepções prévias como para avaliação da aprendizagem.

O jogo Níveis corresponde a segunda opção da tela inicial do OA (Figura 1), um jogo de associação para o estabelecimento de relações entre os diferentes níveis de representações dos conhecimentos químicos (macroscópico, submicroscópico e simbólico), discutido por Johnstone (1993). Para ilustração dos modelos moleculares 
foram considerados o Modelo Atômico de Dalton para a constituição da matéria.

Ao ser selecionada surge a tela apresentada na Figura 8, composta por quadros com imagens da representação da aplicação macroscópica, do modelo submicroscópico, do nome e da fórmula química (ou símbolo químico) de algumas substâncias e um elemento químico, além do botão para retornar ao menu inicial (Voltar ao Menu).

Figura 8: Tela inicial do jogo "Níveis" do OA

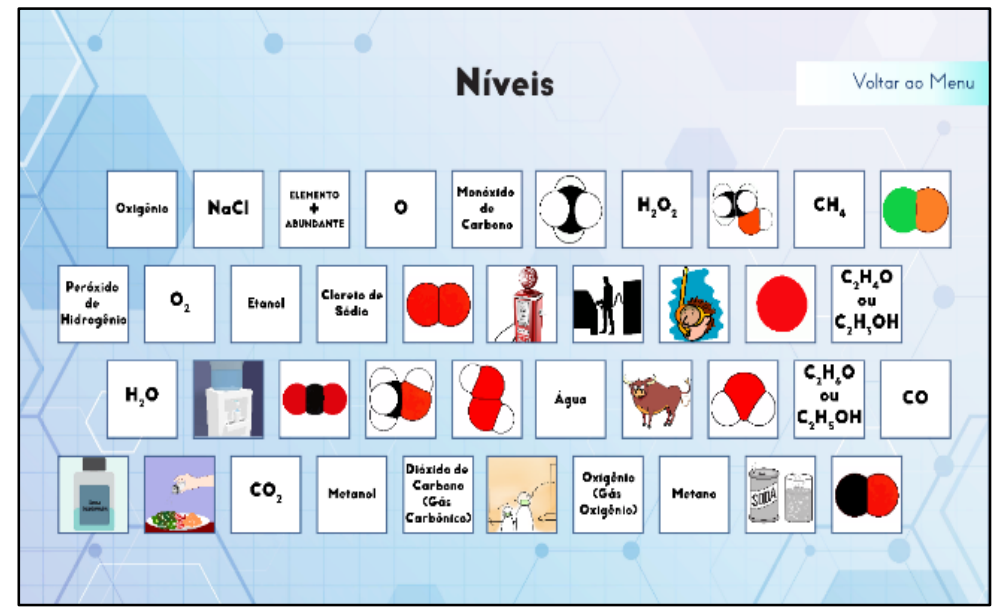

Fonte: Autoras

Estes quadros devem ser relacionados, considerando-se que para cada substância, e o elemento, há quatro representações: o nome, a fórmula química (ou 
símbolo), um objeto/material/situação em que esta substância está presente, e uma partícula da substância.

Conforme o jogador escolhe os quadros associados estes adquirem um contorno colorido, indicando que foram selecionados, conforme Figura 9.

Figura 9: Tela jogo 2 com quadros selecionados

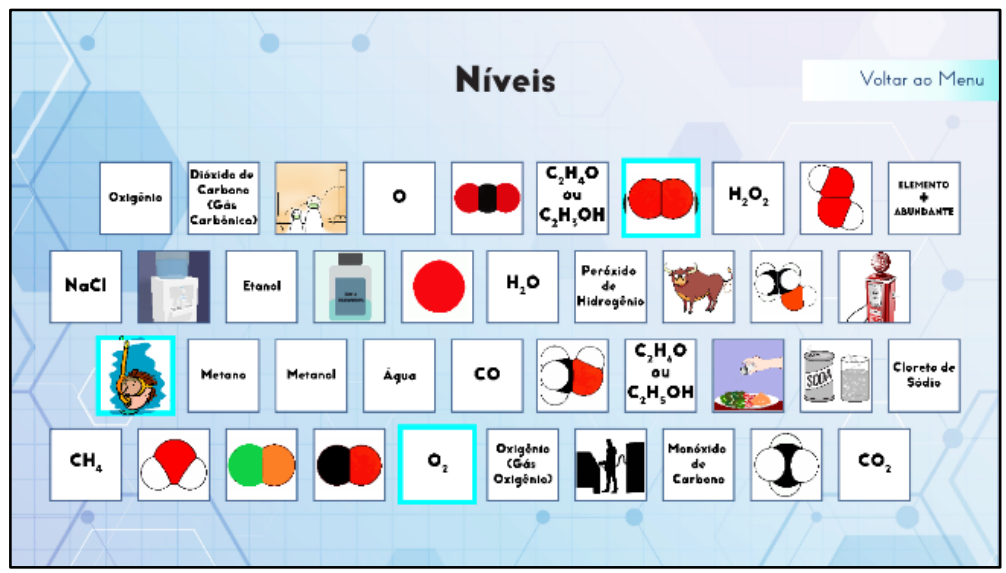

Fonte: Autoras

Quando o quarto quadro é selecionado, independente dos tipos de representações indicadas, a associação realizada é automaticamente corrigida. Se a associação realizada estiver incorreta, isto é, se não foram selecionadas as quatro diferentes representações correspondentes a mesma substância ou elemento, os quadros selecionados terão um contorno vermelho por alguns instantes, como demonstrado na Figura 10 e, em seguida, permane- 
cerão na tela, sem contorno colorido, para uma nova associação.

Figura 10: Tela do jogo 2 com associação incorreta

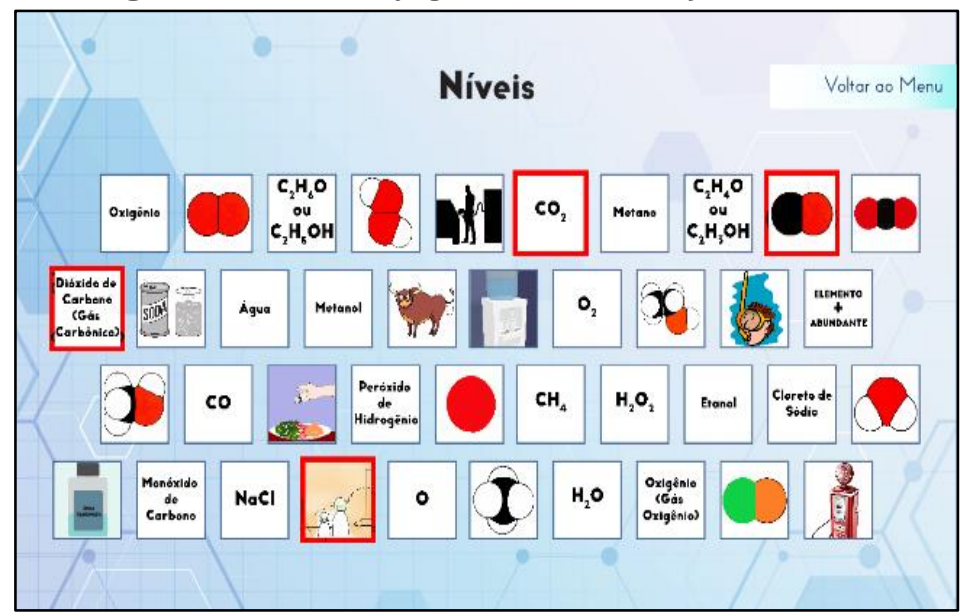

Fonte: Autoras

Já se o jogador acerta a associação, os quadros adquirem um contorno verde por alguns instantes e logo em seguida ficam vazios, indicando que as imagens referentes à substância ou elemento já foram associadas e, portanto, não participam mais do jogo, como demonstrado nas telas da Figura 11. 
Figura 11: Telas do jogo 2 após associação correta

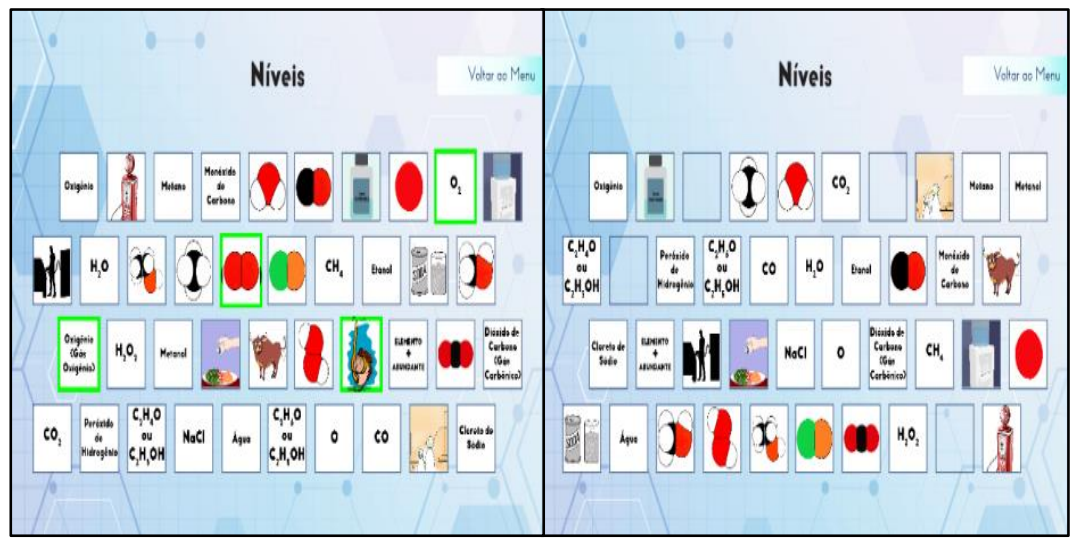

Fonte: Autoras

O jogo termina quando todas as associações forem realizadas e a pontuação dependerá tanto do tempo desprendido quanto da quantidade de erros cometidos.

Deste modo, quando concluídas todas as associações, surge uma tela, apresentada na Figura 12, com a indicação do fim do jogo, os pontos obtidos e as opções Voltar ao Menu, que retorna à tela inicial do OA (Figura 1), ou Jogar Novamente, que retorna à tela inicial do jogo 2 (Figura 8). 
Figura 12: Tela final do jogo 2

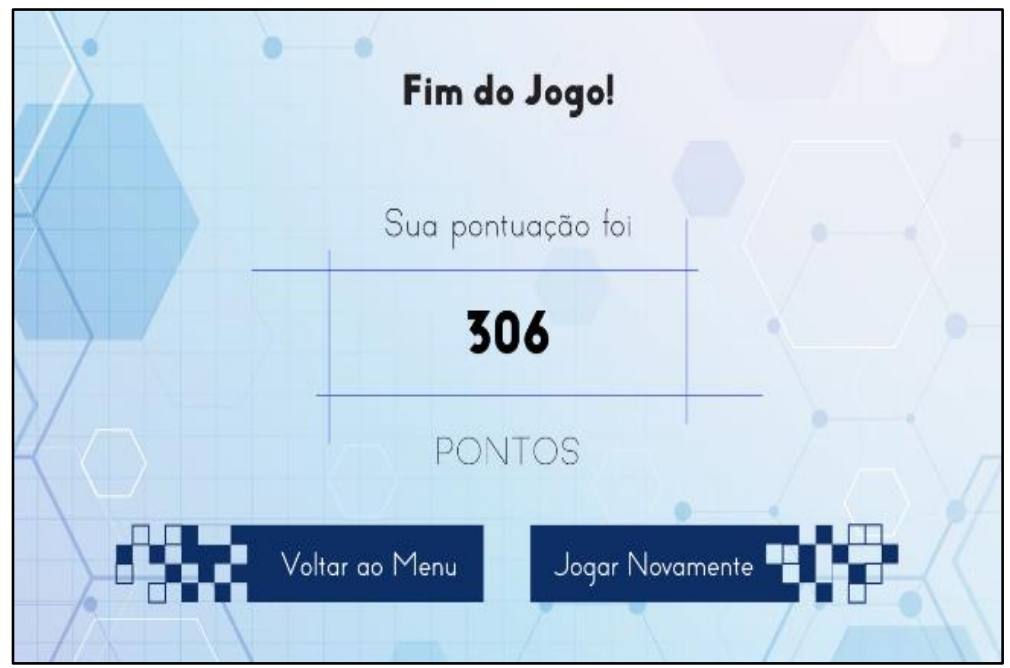

Fonte: Autoras

\section{Jogo "ZoOM"}

Este terceiro jogo objetiva relacionar as escalas e materiais em diferentes níveis, do macroscópico ao submicroscópico. A compreensão da constituição da matéria de acordo com as dimensões abordadas foi uma dificuldade dos estudantes percebida durante a aplicação das atividades didáticas da pesquisa, razão pela qual este jogo foi idealizado e desenvolvido.

O jogo zoOM corresponde a terceira opção da tela inicial do OA (Figura 1). Selecionada esta opção surge uma tela contendo o título do jogo, as opções Voltar ao 
Menu e $O K$, bem como imagens que representam a matéria em um uma progressão escalar, do nível atômico até o macroscópico, bem como as respectivas dimensões na escala métrica, conforme Figura 13.

Figura 13: Tela inicial do jogo 3 "zoOM"

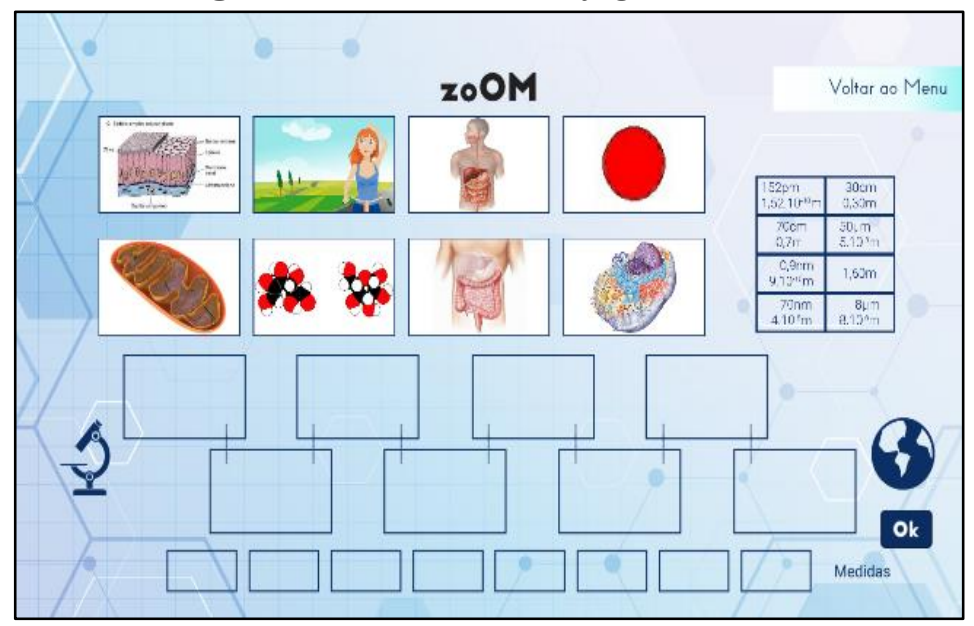

Fonte: Autoras

O jogador deve organizar estas representações em ordem crescente, arrastando as imagens até uma posição na reta, e associar uma medida a estas, arrastando o valor correspondente a dimensão de cada representação, como demonstrado nas telas na Figura 14(a). 
Figura 14: Telas do jogo 3 após associação

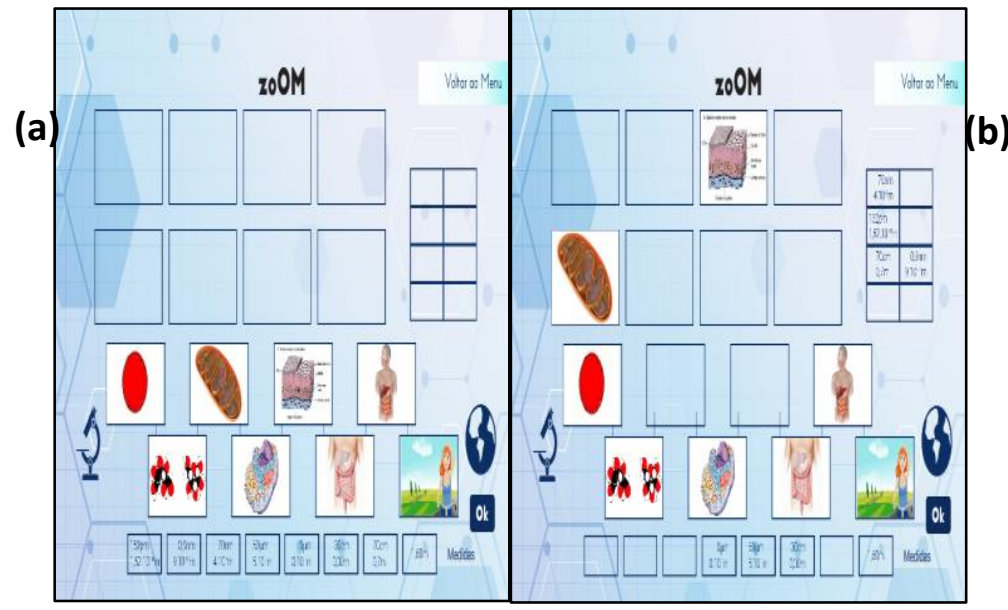

Fonte: Autora

Concluída a organização, o jogador deve selecionar a opção $O K$ para correção da mesma. Se houver associações indevidas o jogo retira imediatamente da reta as imagens incorretas, cabendo ao jogador realizar nova organização destas, como exemplo na Figura 14(b).

Se a organização das imagens e medidas estiver totalmente correta o jogo termina, surgindo uma tela (Figura 15) com a indicação do fim do jogo, a pontuação e as opções Voltar ao Menu, que retorna à tela inicial do OA (Figura 1), ou Jogar Novamente, que retorna à tela inicial do jogo 3 (Figura 13). 
Figura 15: Tela final do jogo 3

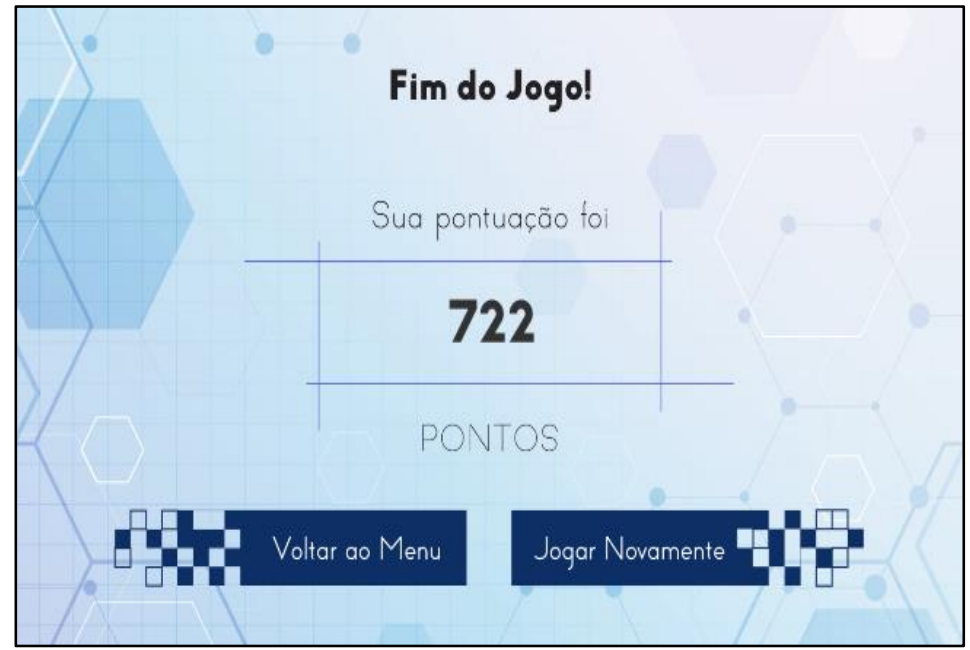

Fonte: Autoras

A pontuação obtida depende do tempo empregado e da quantidade de acertos e erros para obtenção da organização correta.

\section{Conclusões}

O Objeto de Aprendizagem Signos Químicos foi criado e desenvolvido para auxiliar no processo de ensino e aprendizagem das representações químicas, e, portanto, propiciar uma alternativa didática diante da escassez de materiais didáticos elaborados para este fim. 
A introdução e explicitação dos conceitos representação, modelo e símbolo, abordados no jogo Isto é..., podem facilitar o entendimento e apropriação das diferentes representações químicas, evitando dificuldades de interpretação no uso de analogias, metáforas e modelos.

Já a associação dos diferentes modos de representação, como a requerida no jogo Níveis, pode propiciar o reconhecimento e relação dos níveis de pensamento e representação macroscópico, submicroscópico e simbólico da matéria.

E classificar em ordem de grandeza as representações de seres e seus constituintes, como no jogo zoOM, pode facilitar a compreensão das dimensões da matéria pelos estudantes, que é um entrave identificado.

Além de suas potencialidades pedagógicas, por caráter de OA, os jogos digitais deste produto educacional podem ser utilizados de forma independente ou combinados, em diferentes contextos educativos, assim como em momentos diversificados na ação didática.

Ademais, Signos Químicos é um recurso de fácil acesso, por ser de domínio público, bem como de fácil utilização e execução, por ser digital e off-line.

Assim, por tais características, o uso deste produto educacional, como uma ferramenta didática na Educa- 
ção Básica, mostra-se adequado e promissor para o ensino de Química.

\section{Referências}

BRASIL. Ministério da Educação. Base Nacional Comum Curricular. Brasília, DF: MEC, 2018. Disponível em: $<$ http://basenacionalcomum.mec.gov.br/images/BNCC_EI_E F_110518_versaofinal_site.pdf >. Acesso em: 28 out. 2020.

BRASIL. Coordenação de Aperfeiçoamento de Pessoal de Nível Superior. EduCAPES. 2020. Disponível em: <https://educapes.capes.gov.br/>. Acesso em: 30 out. 2020.

CHASSOT, A. Alfabetização científica: uma possibilidade para a inclusão social. Revista Brasileira de Educação, n. 22, p. 89100, 2003. Disponível em: $<$ https://www.scielo.br/pdf/rbedu/n22/n22a09.pdf $>$. Acesso em: 29 out. 2020.

GOIS, J.; GIORDAN, M. Semiótica na Química. Cadernos Temáticos de Química Nova na Escola, n.7, 2007. Disponível em: <http://qnesc.sbq.org.br/online/cadernos/o7/ao6.pdf >. Acesso em: 29 out. 2020.

JOHNSTONE, A. H. Macro and micro-chemistry. The School Science Review, p. 364-377, 1982.

JOHNSTONE, A. H. The Development of chemistry teaching: A changing response to changing demand. Journal of Chemical Education, n. 70, p. 701-704, 1993. Disponível em: $<$ https://pubs.acs.org/doi/abs/10.1021/edo70p701>. Acesso em: 29 out. 2020. 
MACHADO, A. H.; MORTIMER, E. F. Química para o Ensino Médio: Fundamentos, pressupostos e o fazer cotidiano. In: MALDANER, O. A.; ZANON, L. B. (org.). Fundamentos $e$ propostas de ensino de química para a educação básica no Brasil. Ijuí: Unijuí, p. 23-41, 2012.

MORTIMER, E. F.; MACHADO, A. H.; ROMANELLI, L. I. A Proposta Curricular de Química do Estado de Minas Gerais: Fundamentos e Pressupostos. Química Nova, v.23, n.2, p. 273283, 2000. Disponível em: <http://static.sites.sbq.org.br/quimicanova.sbq.org.br/pdf/Vo l23No2_273_V23_n2_\%2821\%29.pdf >. Acesso em: 29 out. 2020.

NOTH, W. Panorama da Semiótica: de Platão a Peirce. São Paulo: Annablume, 1995.

PEIRCE, C. S. Semiótica. Trad.: COELHO NETO, J. T. 2.ed. São Paulo: Perspectiva, 1995.

REINALDO, T. A. S. Representação em Química: relações entre níveis do conhecimento e seus signos para apropriação da linguagem química. 2019. 194 f. Dissertação (Mestrado em Docência para a Educação Básica) - Faculdade de Ciências, Universidade Estadual Paulista "Júlio de Mesquita Filho", Bauru, 2019a. Disponível em: $<$ https://repositorio.unesp.br/handle/11449/181628>. Acesso em: 27 out. 2020.

REINALDO, T. A. S. Signos Químicos. 2019b. Disponível em: $<$ http://educapes.capes.gov.br/handle/capes/582263>. Acesso em: 30 out. 2020.

SABBATINI, M. Reflexões críticas sobre o conceito de objeto de aprendizagem aplicado ao Ensino de Ciências e Matemática. Em Teia - Revista de Educação Matemática e Tecnológica 
Iberoamericana, v. 3, n. 3, p. 1-36, 2012. Disponível em: $<$ https://periodicos.ufpe.br/revistas/emteia/article/view/218 9>. Acesso em: 29 out. 2020.

SANTAELLA, L. O que é semiótica. 26.reimp da 1.ed. (1983). São Paulo: Brasiliense, 2007.

SAVI, R.; ULBRICHT, V. R. Jogos digitais educacionais: benefícios e desafios. RENOTE - Revista Novas Tecnologias na Educação. v. 6, n. 2, p. 1-10, 2008. Disponível em: <https://seer.ufrgs.br/renote/article/view/14405/8310>. Acesso em: 29 out. 2020. 